\title{
A Study on the Media Literacy Through an Analysis on SNS Writing Errors of Adults with Mild Intellectual Disabilities
}

\author{
Soyeon Lim', Whasoo Kim² \\ 'Department of Speech Pathology, Graduate School of Daegu University, Gyeongsan, Korea \\ ${ }^{2}$ Department of Speech Pathology, Daegu University, Gyeongsan, Korea
}

Received: April 30, 2020
Revised: June 5, 2020
Accepted: July 7, 2020
Correspondence:
Whasoo Kim, PhD
Department of Speech Pathology,
Daegu University,
201 Daegudae-ro, Jillyang-eup,
Gyeongsan 38453, Korea
Tel: +82-53-850-4324
Fax: +82-53-850-4329
E-mail: whasoolang@hanmail.net

\begin{abstract}
Purpose: The purpose of this preliminary research attempted for media literacy from a linguistic perspective was to analyze writing errors in social network service (SNS) usage on adults with mild intellectual disabilities and to use it as preliminary data of writing education using media such as SNS. Methods: A total of 30 peoples (15 for adults with mild intellectual disabilities and 15 for general adults) participated. Data were extracted writing errors in SNS usage at random and analyzed them qualitatively and quantitatively. Results: The qualitative analysis showed that total score of adults with mild intellectual disability was lower than that of the general adults while there was same pattern in all 5 subcategories. In the quantitative analysis, there was a significant difference in the use of postposition between two groups. Also, both groups showed a positive correlation among three subcategories such as spelling, word spacing, and postposition. Conclusion: This study have significance in conducting an analysis on spontaneity of adults with mild intellectual disabilities that appears on SNS that was not sufficiently attempted previously and this researcher expects the analysis result to be used as a preliminary data of developing writing-related education using media such as SNS.
\end{abstract}

\section{INTRODUCTION}

언어는 영아기부터 노인기에 이르기까지 지속적으로 발달하 며 듣기, 말하기, 읽기, 쓰기 영역으로 이루어져 있다. 그중 쓰기 는 자신의 생각이나 의사를 문자로 표현하는 것으로 복합적인 처리 과정을 필요로 한다. 또한 시공간을 초월한 상황 속 가상 의 독자를 대상으로 하는 언어활동에 해당하여(Lee, 2004), 학 습 장면에서 자주 사용되며 일상생활에서도 자주 직면하게 되 는 과제 중 하나이다. Lee \& Lee(1990)의 연구에서는 한국 아 동 쓰기 발달 단계를 총 6 단계로 말했다. 먼저 초기 유아는 긁적 거리며 종이, 색연필 등에 관심을 가지게 된다. 이후 한두 개의 자형이 우연히 나타나게 되면서부터 글자와 그림이 분화된 형 태를 보이며, 점이나 짧은 선으로 글자를 표현하게 된다. 학령기 로 넘어가게 되면 온전한 글자 형태가 나타나고, 학령기 중기에 서 후기로 넘어가게 되면 완전한 단어 형태가 나타나기 시작하 여 틀린 글자 없이 완전한 문장 형태가 나타나게 된다. 이처럼

(cc) This is an Open Access article distributed under the terms of the Creative Commons Attribution Non-Commercial License (https://creativecommons.org/licenses/by-nc/4.0) which permits unrestricted non-commercial use, distribution, and reproduction in any medium, provided the original work is properly cited.
쓰기 발달은 유아의 몸짓이나 긁적이기부터 시작하여 점차 관 습적 형태로 발전해 나가며, 학령기에 들어가게 되면 본격적으 로 일정한 글자를 쓰는 것, 생각을 글로 표현하는 것, 탈상황적 인 이야기를 쓰는 것 등으로 발전해 나간다. 쓰기가 원활하게 이루어지기 위해서는 어휘가 풍부해야 할 뿐 아니라 인과관계, 조직성, 일관성, 계획화 등의 기술에 어려움이 없어야 하며 정 확하게 문장을 구조화시킬 수 있어야 한다. 또한 전체적인 글의 완성도를 높이기 위해서는 위와 같은 기술들과 더불어 띠어쓰 기, 맞춤법, 조사 사용 등 문법적인 요소들과 문장 구성 능력, 논리성 등이 뒷받침되어야 한다.

하지만 지적장애 아동의 발달을 살펴보면, 또래와 같은 순서 를 보이기는 하나 더 미성숙한 특성을 보이며(Son et al., 2013), 읽기와 쓰기와 같은 문해 능력은 같은 언어연령을 일치시킨 아 동보다 현저히 떨어진다. 지적장애 학생의 쓰기 특성은 낱말의 종성을 생략, 대치하거나 연음으로 글을 표기하는 오류의 빈도 가 높으며 음운이나 음소에 대한 결함이 있을 경우 낱말의 본 모 습을 다른 형태로 표기하는 오류를 자주 나타낸다(Kim, 2002). 뿐만 아니라 학습을 위한 필수적인 언어능력에 어려움이 있어 쓰기를 통한 사고 활동과 자기 표현에 한계를 지니고 있으며 언 
어 규칙을 일반화하는 능력이 부족하여 길이가 짧고 단순한 문 장을 사용하는 경향을 보인다(Kang, 2007). 같은 맥락으로 Lee (1994)의 연구에서도 지적장애 학생의 쓰기 특성은 구두점, 철 자법, 문법 등에서의 성취 수준이 낮고 글의 응집력이 떨어지며 작문당 단어의 수가 적게 나타났다. 또 새로운 형식의 구문을 이 해하고 학습하는 데 더 큰 노력이 필요하며, 구문 구조 발달의 비율 또한 일반 아동에 비해 느린 모습을 보인다(McLeavey et al., 1982). 사회적 의사소통 능력 또한 화용 능력의 결함으로 매 우 느린 발달을 보이며(Kim, 1991; Kim \& An, 2017), 그로 인 해 대인관계와 사회적 상호작용에서도 어려움을 보인다. 지적장 애 아동의 언어 발달 부진이 청소년기를 지나 성인기까지 이어 지게 되면, 심화된 학습과 사회생활에서의 제한으로 인해 사회 적 의사소통 곤란으로 이어질 수 있다. 또한 상징적이고 복합적 인 구문 이해, 대화 수정, 대화 참여 등에서도 어려움을 보일 수 있고 짧은 발화, 빈약한 어휘, 문법형태소 생략 등의 양상이 두드러지게 나타날 수 있다.

한편 정보 통신 기술의 발달로 스마트폰과 스마트패드 등의 미디어 보급이 매우 증가하고 있다. 미디어란 정보를 전달하는 매체라는 뜻으로 현대 사회에서는 자신의 감정과 의사를 표현 하고 객관적인 정보를 주고받는 수단으로 활용하고 있다. 미디 어를 통해 정보를 얻고 자신의 의사를 표현하기 위해서는 미디 어 문식성(media literacy), 즉 다양한 매체의 특성을 이해하여 내용을 평하고 의사소통할 수 있는 능력이 매우 중요하다. 그중 소셜 네트워크 서비스(social network service, SNS)로 불리는 소셜 미디어는 서로 생각이나 의견을 공유하며 사회적 관계망 을 넓혀나갈 수 있는 플랫폼으로 그 사용자의 비율이 점차 증 가하고 있다(Kim \& Han, 2008; Lee et al., 2013; Lee \& Yoon, 2011). SNS란 사람들과 활동, 정보, 실생활 등을 공유하며 사회 적인 관계를 맺을 수 있는 온라인 기반의 서비스(Lim et al., 2012)로 시공간의 제약이 없고 상호작용을 촉진한다는 장점이 있어 최근에는 교육적으로도 많이 활용되고 있다(Kim \& Han, 2008; Lee \& Yoon, 2011; Lee et al., 2013). SNS를 활용 하여 쓰기 교육을 실시한다면, 학생 자신이 독자를 고려하여 글을 쓰게 됨으로써 글쓰기의 필요성을 자각할 수 있으며 글에 대한 흥미와 관심, 동기를 불러일으킬 수 있다(Choi et al., 2007; Lee, 2010). 또 키보드나 키패드 사용은 수정이 간편하여 필기구 로 쓸 때보다 거부감을 줄일 수 있고, 쓰기 능력에도 긍정적인 영향을 미치게 된다(Kim \& Han, 2008; Yoon \& Lee, 2014). SNS와 같은 소셜 미디어가 발전함에 따라 사회적으로 다양한 문화들이 유행하고 있는데, 그중 언어 사용의 변화는 소셜 미 디어상에서 유행하는 다양한 문화 중 빠질 수 없는 요소이다. 예로는 유행어, 신조어, 준말 등으로 이러한 언어 사용은 개인 의 개성이나 특성을 잘 나타내 주기도 하며 타인과 적절한 관계
를 유지하기 위한 매우 중요한 요소이기 때문에 청소년들과 20 대 성인은 이를 유연하게 받아들여 빠르게 적응하고 활용해 나 간다. 또 일반 청소년들과 20 대 성인의 SNS 내 주된 활동은 평 점 주기 참여, 정보 공유, 답변이나 글 작성(Choi, 2017) 등으로 홍보의 목적이 아닌 대부분은 친구나 지인들과의 소통 및 관계 유지를 위하여 사용한다. 최근 SNS를 활용한 의사소통은 가까 운 친구, 지인과 주로 활동하던 제한된 형태를 거쳐 전 세계 사 람들과의 소통으로 그 범위가 더욱 확대되었다(Lee, 2015). 이 처럼 SNS는 시공간의 제약 없이 다양한 사람들과 관계를 맺을 수 있고 변화하는 현대 사회에 유연하게 적응하여 새로운 정보 를 얻고 자신의 활동을 공유할 수 있는 매우 중요한 의사소통 수단으로 자리 잡고 있으나, 상대적으로 지적 능력과 언어 능력 이 부족한 아동이나 성인의 경우에는 SNS 내에서 자주 사용되 는 새로운 형태의 언어 사용과 활용에도 제한을 보일 수 있다.

특히 경도지적장애 성인들의 언어 특성을 살펴보면, SNS에서 자주 사용되는 언어 사용 등과 밀접한 관계를 맺고 있는 관용 어, 비유 언어를 이해하지 못하여(Jang, 2016), 유행어, 신조어, 준말 등의 이해와 사용에서 어려움을 보이며, 아동기의 문해 능력 부진이 이어져 성인기에서도 다양한 쓰기 오류들이 나타 나게 된다. 특히 아동기부터 이어진 언어 특성 가운데 구문 이 해 능력 결함과 더불어 구두점, 철자법, 문법 등에서의 제한과 낱말의 종성을 생략, 대치하거나 다른 형태로 표기하는 오류를 자주 나타낼 경우 SNS 활용에도 영향을 미쳐 쓰기에서의 어려 움으로 이어질 수 있다. SNS상의 지속적인 쓰기 오류는 원만 한 사회적 의사소통에 있어 부정적인 영향을 끼칠 수 있으며 상대방과 적절한 관계를 유지하는 것, 새로운 정보를 얻고 활 용하는 것 등의 어려움이 있을 수 있다. 따라서 시간과 공간의 제약 없이 타인과 소통하는 현대 사회를 살아가기 위해서는 학 습을 위한 문해 능력뿐 아니라 미디어상에서의 문해, 특히 쓰기 능력이 필수적이라고 할 수 있다(Graham et al., 2007; Olson \& Oatley, 2014).

경도지적장애 성인은 다른 장애군들에 비하여 사회의 일원 으로서 타인과 관계를 형성하는 과정에 비교적 많이 노출되나 변화되는 사회 속에서 접할 수 있는 미디어 문식성과 관련된 교육은 부족한 실정이다. 따라서 다양한 접근을 통해 언어 및 문해 능력을 향상시킬 수 있는 방법 모색이 필요하며, 지적장애 청소년 또는 성인을 대상으로 하는 체계적이고 전문적인 쓰기 교육이 필요하다(Jung \& Lee, 2008).

전술한 내용과 같이 미디어 보급의 증가로 사회적인 변화뿐 아니라 언어 사용에도 큰 변화를 맞고 있으나 미디어 문식성과 관련된 언어학적 연구는 거의 찾아볼 수 없으며, 특히 SNS 사 용을 활용한 쓰기 교육 연구가 존재하기는 하나 매우 미비하 다. 뿐만 아니라 국내 쓰기 관련 연구 동향을 분석해 보았을 
때, 일반 아동을 대상으로 하는 쓰기 연구는 활발하게 진행되 고 있는 반면 지적장애 청소년, 특히 성인을 대상으로 하는 연 구는 부족한 실정이다.

따라서 본 연구는 언어학적 관점에서의 미디어 문식성을 위해 시도된 예비연구로서, 경도지적장애 성인을 대상으로 하여 SNS 사용에서 나타나는 쓰기 오류를 분석하고자 하였으며 이를 토 대로 SNS와 같은 미디어를 활용한 쓰기 관련 교육의 기초 자료 로 활용되기를 기대해 본다. 본 연구의 연구 문제는 다음과 같다.

1) 두 집단(경도지적장애 성인, 일반 성인) 간 질적 평가에서 의 쓰기 오류의 차이는 어떠한가?

(1) 두 집단 간 전체 점수 차이는 어떠한가?

(2) 두 집단 간 전반적 인상, 맞춤법/문장 부호, 단어 사용, 조 사 사용의 적절성, 띄어쓰기 사용 간 점수 차이는 어떠한가?

2) 두 집단(경도지적장애 성인, 일반 성인) 간 양적 평가에서 의 쓰기 오류의 차이는 어떠한가?

(1) 두 집단의 맞춤법, 띄어쓰기, 조사 사용의 적절성 점수 차 이는 어떠한가?

3) 두 집단(경도지적장애 성인, 일반 성인)별 하위 범주 간 상 관관계는 어떠한가?

(1) 경도지적장애 성인 집단의 하위 범주 간 상관관계가 있 는가?

(2) 일반 성인 집단의 하위 범주 간 상관관계가 있는가?

\section{MATERIALS AND METHODS}

\section{연구 대상}

본 연구의 대상은 대구광역시에 거주하는 만 19 21세인 경도 지적장애 성인 15 명과 대구광역시의 대학교에 재학 중인 일반 성인 15 명으로 총 30 명이었다. 대상자 선정 기준은 아래와 같다.

경도지적장애 성인 집단 선정 기준

(1) 병원이나 사설기관에서 경도지적장애인으로 진단받은 성인

(2) Korean Wechsler adult intelligence scale-IV (K-WAISIV) 결과, Full Scale Intelligence Quotient (전체 IQ)가 50 이 상 70 이하에 해당하는 성인

(3) 수용·표현 어휘력 검사 결과, 표현언어 능력이 13 세 이상 인 성인

(4) 시각, 청각 등 신체적 장애를 수반하지 않은 성인

일반 성인 집단 선정 기준

(1) 수용·표현 어휘력 검사 결과 표현언어 능력이 16 세 이상 인 성인

(2) 신체장애, 행동장애, 지적장애 등 기타 장애를 수반하지 않은 성인

연구에 참여한 대상자 정보는 아래 Table 1과 같다.

경도지적장애 성인 집단과 일반 성인 집단 간 성별과 생활연 령의 동질성 검증과 언어연령을 비교하기 위하여 독립표본 $t-$ 검정을 실시하였다. 생활연령 검증을 위하여 전체 집단의 연령 을 월령으로 계산하였다. 실시 결과 성별과 생활연령에서 유의

Table 1. Comparison of characteristics between participants

\begin{tabular}{|c|c|c|c|c|c|c|}
\hline \multicolumn{5}{|c|}{ Adults with mild intellectual disabilities } & \multicolumn{2}{|l|}{ General adults } \\
\hline No. & Chronological age (month) & Sex & REVT-E (age) & K-WAIS-IV & Chronological age (month) & Sex \\
\hline 1 & 233 & M & 13 & 58 & 235 & $\mathrm{~F}$ \\
\hline 2 & 229 & M & Over the age of 16 & 63 & 241 & $\mathrm{~F}$ \\
\hline 3 & 246 & $\mathrm{~F}$ & 15 & 63 & 244 & $\mathrm{~F}$ \\
\hline 4 & 232 & $\mathrm{~F}$ & 14 & 55 & 230 & M \\
\hline 5 & 229 & $\mathrm{~F}$ & 13 & 53 & 235 & $\mathrm{M}$ \\
\hline 6 & 235 & $\mathrm{~F}$ & 14 & 57 & 230 & $\mathrm{M}$ \\
\hline 7 & 244 & M & 13 & 60 & 231 & $\mathrm{M}$ \\
\hline 8 & 241 & $\mathrm{~F}$ & 14 & 62 & 234 & $\mathrm{~F}$ \\
\hline 9 & 233 & $\mathrm{~F}$ & 14 & 63 & 241 & $\mathrm{M}$ \\
\hline 10 & 232 & M & 13 & 59 & 234 & $\mathrm{M}$ \\
\hline 11 & 235 & $\mathrm{~F}$ & 13 & 59 & 244 & $\mathrm{~F}$ \\
\hline 12 & 245 & $\mathrm{~F}$ & 13 & 57 & 246 & $\mathrm{M}$ \\
\hline 13 & 229 & M & Over the age of 16 & 67 & 245 & $\mathrm{M}$ \\
\hline 14 & 247 & M & 13 & 61 & 236 & $\mathrm{M}$ \\
\hline 15 & 229 & $\mathrm{~F}$ & 15 & 63 & 235 & $\mathrm{~F}$ \\
\hline
\end{tabular}

REVT: receptive \& expressive vocabulary test, K-WAIS-IV: Korean Wechsler adult intelligence scale-IV, M : male, F : female 
미한 차이를 보이지 않아 두 집단의 성별과 생활연령에서의 차 이가 없는 것으로 나타났으며 $(t=-0.648, t=1.080)$, 언어연령 에서 유의미한 차이가 나타나 두 집단의 언어연령에서의 차이 가 존재하는 것으로 나타났다 $(t=-15.899)$.

생활연령 동질성 검증 실시 결과는 Table 2 와 같다.

\section{검사 도구}

수용·표현 어휘력 검사(Receptive \& expressive vocabulary test)

경도지적장애 성인과 일반 성인의 언어연령을 맞추기 위한 평가도구로 수용·표현 어휘력 검사(receptive \& expressive vocabulary test) (Kim et al., 2009) 가운데 표현 어휘력 검사를 실시하여 표현 어휘력이 13 세 이상으로 나타나는 지적장애 성 인 15 명과 생활연령이 일치하는 일반 성인 15 명을 선정하였다.
한국 웩슬러 성인지능검사 4판(Korean Wechsler adult intelligence scale-IV)

경도지적장애 성인의 지능지수를 판별하기 위한 평가도구로 한국 웩슬러 성인지능검사 4판(K-WAIS-IV) (Hwang et al., 2012)을 실시하여 지능지수가 50 이상 70 이하로 나타나는 지 적장애 성인 15 명을 선정하였다.

\section{쓰기 오류 분석}

경도지적장애 성인 15 명과 일반 성인 15 명의 $\mathrm{SNS}$ (카카오톡, 페이스북, 인스타그램) 활동 중 게시물, 댓글 등에서 나타나는 문장을 SNS별 10 문장씩, 즉 1 명당 총 30 문항씩 추출하여 한글 파일에 정리한 뒤 분석하였다. 문장의 양은 두 집단 내 대상자 별 전체 문장(30문항)의 음절 수 차이를 10 음절 이내로 맞추었 다. 쓰기 오류 분석은 질적 평가와 양적 평가로 나누어 실시하 였다. 질적 평가 준거는 Yu \& Jeong(2008)의 연구 내 평가 항 목과 배점을 본 연구에 맞도록 연구자가 수정·보완하였고 양적 평가 준거 또한 $\mathrm{Yu}(2010)$ 의 연구 내 평가 항목과 오류 처리 공 식을 연구에 맞도록 연구자가 수정·보완하여 사용하였다.

Table 2. Results of verification of homogeneity of chronological age

\begin{tabular}{|c|c|c|c|c|c|c|}
\hline \multirow{2}{*}{ Category } & \multicolumn{2}{|c|}{ Adults with mild intellectual disabilities } & \multicolumn{2}{|c|}{ General adults } & \multirow{2}{*}{$t$} & \multirow{2}{*}{$p$} \\
\hline & Mean & $\mathrm{SD}$ & Mean & $\mathrm{SD}$ & & \\
\hline Gender & 1.6 & 0.507 & 1.4 & 0.507 & -0.648 & 0.522 \\
\hline Chronological age & 235.9 & 6.756 & 237.4 & 5.591 & 1.080 & 0.289 \\
\hline REVT-E & 172.7 & 10.347 & 217.8 & 3.668 & -15.899 & $<0.001$ \\
\hline
\end{tabular}

REVT: receptive \& expressive vocabulary test, SD: standard deviation

Table 3. Qualitative evaluation standard

\begin{tabular}{clll}
\hline Assessment methods & Assessment category & Assessment standard & Distribution \\
\hline Overall assessment & Overall impression & Is the meaning, connection, and use of the sentence & Good 2 \\
& & appropriate? & Usually 1.5 \\
Analytical assessment & Detailed impression & Are spelling smooth without errors? & Bad 1 \\
& & Was the word used abundantly without repetition? & (distribution equal to the overall \\
& & Is the meaning appropriate without any errors & evaluation) \\
& in postposition use? & Total score 8 \\
& Are there any spacing words errors? & 10 \\
& Total score & \\
\hline
\end{tabular}

Table 4. Quantitative evaluation standard

\begin{tabular}{|c|c|}
\hline Type & Formula \\
\hline \multirow{6}{*}{ Text language knowledge } & \multirow{2}{*}{ Spelling error rate $=\frac{\text { Number of words with spelling errors }}{\text { Total number of words }} \times 100$} \\
\hline & \\
\hline & Number of word spacing errors in a sentence \\
\hline & Total number of word spacing \\
\hline & Number of postposition errors \\
\hline & Total number of used postpositions \\
\hline
\end{tabular}


분류한 결과는 Table 3,4 와 같다.

Table 3은 질적 분석에 해당하는 표이다. 평가 방법은 총체 적 및 분석적 평가로, 총체적 평가는 전반적 인상, 분석적 평가 는 세부적 인상으로 나뉜다. 세부적 인상에 해당하는 하위 범 주는 맞춤법, 단어 사용, 조사 사용의 적절성, 띄어쓰기로 이루 어져 있으며, 총 하위 범주는 전반적 인상과 합하여 총 5 가지로 구성되어져 있다. 배점은 좋음 $=2$ 점, 보통 $=1.5$ 점, 나쁨 $=1$ 점 으로 맞춤법, 조사 사용의 적절성, 띄어쓰기는 한 문장 내에서 오류가 없을 경우 2점, 1 개의 오류가 나타났을 경우 1.5 점, 2개 이상의 오류가 나타났을 경우 1점으로 분석하였고 단어 사용 은 어휘 다양도가 0.8 1이면 2점, 0.4 0.7이면 1.5점, 0.1 0.3이 면 1점으로 분석하였다. 분석은 언어치료 경력 10년 이상이면 서 언어재활사 1 급을 소지한 1 명과 언어재활사 2 급 자격증을 소지한 1명이 분석하여 백분율로 환산한 뒤, 소수점 첫 번째 자리까지 제시하였다.

Table 4는 양적 분석에 해당하는 표이다. 양적 분석의 하위 범주는 맞춤법, 띄어쓰기, 조사 사용의 적절성으로 구성되어져 있다. 모든 하위 범주에 해당하는 값은 정반응률로 구하기 위 하여, 백분율로 환산하여 산출되는 오류율을 100 에서 뺀 값으 로 변환하여 분석하였다.

\section{내용 타당도}

쓰기 오류 분석 중 질적 평가 내용의 적절성에 대한 검사를 위해 전문가 내용 타당도 검증을 진행하였다. 내용 타당도는 언 어치료 경력 10 년 이상이면서 언어재활사 1 급을 소지한 1 명과 언어재활사 2 급 자격증을 소지한 1명이 검증하였으며, 5 점을 만점으로 하여 5점 척도로 실시하였다. 내용 타당도 검증 결과 평균 4.3점 이상으로 평가 문항을 본 평가로 최종 결정하였다.

\section{평가자 간 신뢰도}

본 연구에서 살펴본 쓰기 오류 분석에 대한 평가자 간 신뢰 도를 검증하기 위하여 언어재활사 1 급 자격증을 소지한 1명과 2급 자격증을 소지한 1명을 선정하여 평가자 간 신뢰도를 산출 하였다. 경도지적장애 성인 집단과 일반 성인 집단의 SNS에서 추출한 문장의 $20 \%$ 를 무작위로 선정하여 질적 쓰기 오류 분 석과 양적 쓰기 오류 분석을 실시하였으며, 평가자 간 신뢰도를 측정한 결과, 질적 쓰기 오류 분석의 일치율은 $93.7 \%$, 양적 쓰 기 오류 분석은 $98.4 \%$ 로 나타났다.

\section{자료 분석}

경도지적장애 성인 집단과 생활연령을 일치시킨 일반 성인 집단 간의 SNS상에서 나타나는 쓰기 오류를 분석하기 위해서 SPSS 25.0(IBM Corp., Armonk, NY, USA)을 사용하였다. 두
집단의 검사 결과를 수치화하였으며, 독립표본 $t$-검정과 Pearson 상관분석을 실시하였다. 독립표본 $t$-검정을 실시한 이유는 양적 분석 시 두 집단 간 차이를 비교하기 위함이었으며, Pearson 상관분석을 통해 하위 범주(맞춤법, 띄어쓰기, 조사) 간 연 관성이 있는가를 알아보기 위해 실시하였다.

\section{RESULTS}

두 집단 오류 문장의 예는 Appendix에 제시하였다.

\section{질적 평가에서의 쓰기 오류 평가 결과}

두 집단(경도지적장애 성인 집단과 생활연령을 일치시킨 성인 집단) 간 전체 점수 결과

전반적 인상, 맞춤법, 단어 사용, 조사 사용의 적절성, 띄어쓰 기의 전체 점수 결과는 Figure 1과 같다.

두 집단 간 전체 점수 결과는 다음과 같다. 전체 점수 결과 경도지적장애 성인 집단은 $90.2 \%$, 일반 성인 집단은 $96.2 \%$ 로 경도지적장애 성인 집단에 비하여 일반 성인 집단의 전체 점수 가 더 높은 것으로 나타났다.

\section{하위 범주 간 점수 결과}

하위 범주(전반적 인상, 맞춤법, 단어 사용, 조사 사용의 적절 성, 띄어쓰기) 간 점수 결과는 Figure 2와 같다.

두 집단의 전반적 인상, 맞춤법, 단어 사용, 조사 사용의 적절 성, 띄어쓰기 간 점수 비교 결과는 다음과 같다. 먼저 전반적 인 상 점수는 경도지적장애 성인 집단은 $83.2 \%$, 일반 성인 집단은 95.3\%로 나타났으며, 맞춤법 점수는 경도지적장애 성인 집단 $89.3 \%$, 일반 성인 집단 $93.5 \%$ 로 나타났다. 단어 사용은 경도지 적장애 성인 집단 $98.8 \%$, 일반 성인 집단 $99.7 \%$ 로 나타났으며 조사 사용의 적절성은 경도지적장애 성인 집단 $92.0 \%$, 일반 성

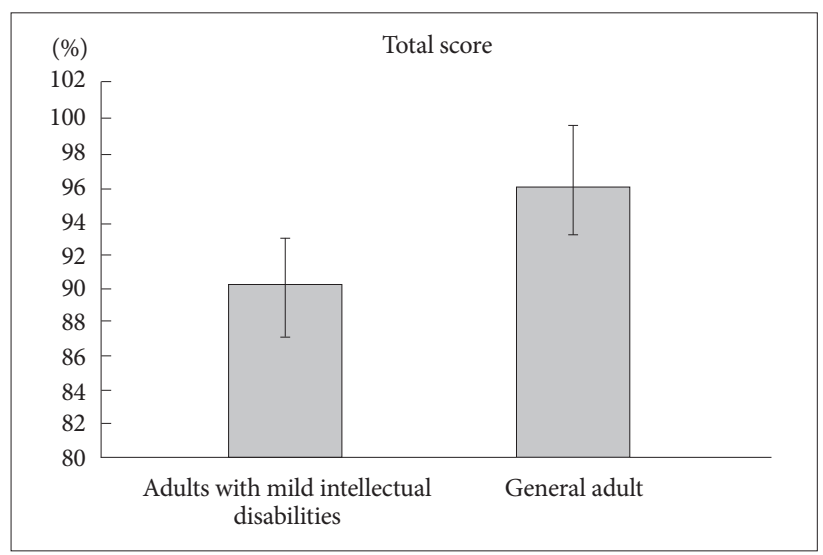

Figure 1. Total score of qualitative evaluation. 


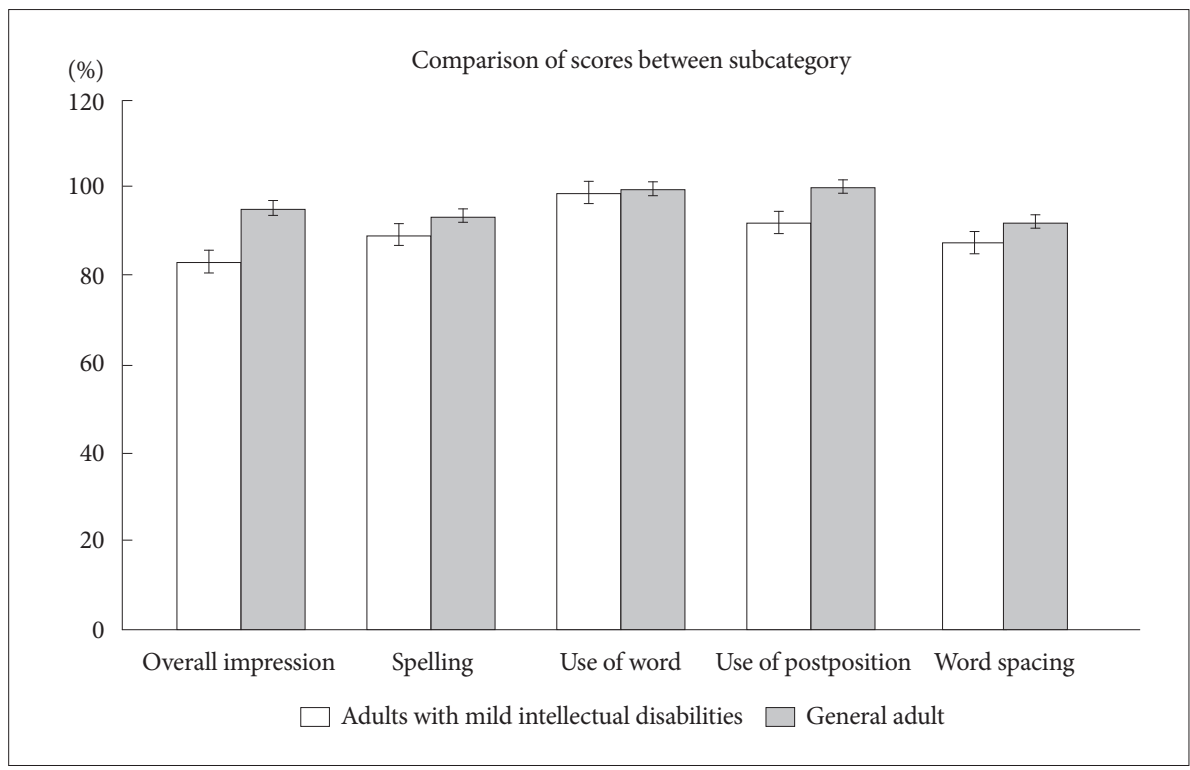

Figure 2. Comparison of scores between subcategory.

Table 5. Two independent samples $t$-test for differences in subcategories between two groups

\begin{tabular}{|c|c|c|c|c|c|}
\hline \multirow{2}{*}{ Category } & \multicolumn{2}{|c|}{ Adults with mild intellectual disabilities $(\mathrm{n}=15)$} & \multicolumn{2}{|c|}{ General adults $(n=15)$} & \multirow{2}{*}{$t$} \\
\hline & Mean & $\mathrm{SD}$ & Mean & $\mathrm{SD}$ & \\
\hline Spelling & 91.60 & 5.68 & 91.80 & 3.65 & -0.115 \\
\hline Word spacing & 64.67 & 31.41 & 74.40 & 16.60 & -1.061 \\
\hline Postposition & 80.73 & 12.86 & 99.94 & 0.26 & $-5.782^{* * *}$ \\
\hline
\end{tabular}

${ }^{* * *} p<0.001$

인 집단 $100 \%$ 로 나타났다. 마지막으로 띄어쓰기 점수 결과 경 도지적장애 성인 집단은 $87.5 \%$, 일반 성인 집단은 $92.3 \%$ 로 총 5 가지의 하위 범주 모두 경도지적장애 성인 집단에 비하여 일반 성인 집단이 높은 것으로 나타났다.

\section{양적 평가에서의 쓰기 오류 평가 결과}

두 집단 간 하위 범주별 쓰기 오류 차이 비교

경도지적장애 성인 집단과 일반 성인 집단의 하위 범주별 차 이를 비교하기 위하여 독립표본 $t$-검정을 실시하였으며, 결과 는 Table 5, Figure 3과 같다.

Table 3에 따르면 경도지적장애 성인과 일반 성인 간 조사 쓰 기오류 $(t=-5.782, p<0.001)$ 에서 유의미한 차이가 나타났다.

\section{두 집단별 하위 범주 간 상관관계 결과}

\section{경도지적장애 성인 집단의 하위 범주 간 상관관계}

경도지적장애 성인 집단의 하위 범주 간 상관관계를 살펴본 결과는 Table 6과 같다.

Table 6의 경도지적장애 성인 집단의 맞춤법, 띄어쓰기, 조사 간 상관관계를 살펴본 결과 조사와 띄어쓰기 간 $(\mathrm{r}=0.652, p<$

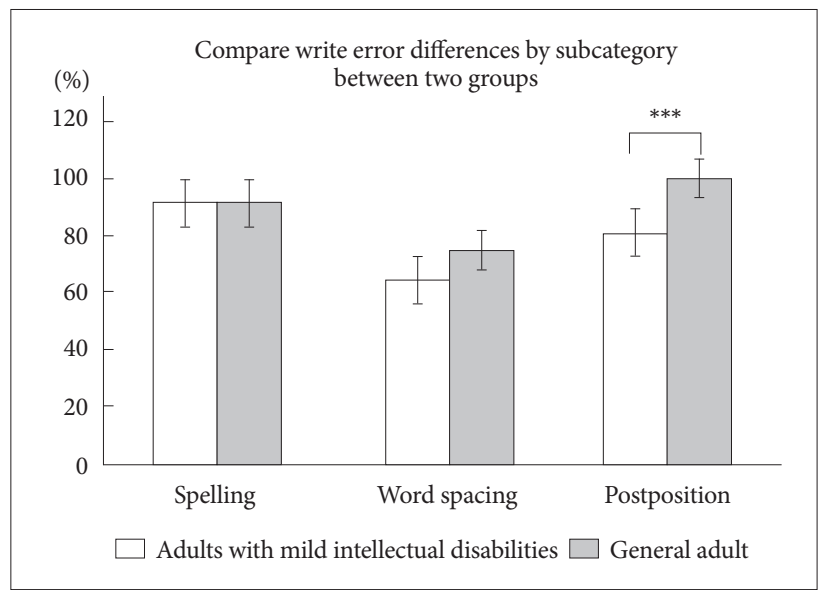

Figure 3. Compare write error differences by subcategory between two groups. ${ }^{* * *}$ An independent sample $t$-test was conducted to compare the differences by subcategory between two groups, resulting in significant difference in compare postposition write errors.

0.01)에 유의미한 정적 상관이 있는 것으로 나타났다.

\section{일반 성인 집단의 하위 범주 간 상관관계}

일반 성인 집단의 하위 범주 간 상관관계를 살펴본 결과는 Table 7과 같다.

Table 7의 일반 성인 집단의 맞춤법, 띄어쓰기, 조사 간 상관 
Table 6. Correlation coefficient between subcategories of the group of adults with mild intellectual disabilities

\begin{tabular}{clccc}
\hline Group & Subcategory & Spelling & Word spacing & Postposition \\
\hline Adults with mild intellectual disabilities & Spelling & 1 & & \\
& Word spacing & -0.133 & 1 & \\
& Postposition & -0.150 & $0.652^{* *}$ & 1 \\
\hline
\end{tabular}

${ }^{* *} p<0.01$

Table 7. Correlation coefficient between subcategories of the group of general adults

\begin{tabular}{llccc}
\hline Group & Subcategory & Spelling & Word spacing & Postposition \\
\hline Adults & Spelling & 1 & & \\
& Word spacing & 0.220 & 1 & \\
& Postposition & -0.156 & $-0.691^{* *}$ & 1 \\
\hline
\end{tabular}

${ }^{* *} p<0.01$

관계를 살펴본 결과 조사와 띄어쓰기 간 $(\mathrm{r}=-0.691, p<0.01)$ 에 유의미한 정적 상관이 있는 것으로 나타났다.

\section{DISCUSSIONS}

본 연구는 경도지적장애 성인과 일반 성인의 SNS상에서 나 타나는 쓰기 오류를 분석하여 차이를 살펴보고자 하였다. 이를 위해 두 집단의 SNS에서 나타난 문장들을 추출하여 질적 분 석과 양적 분석으로 나누어 집단 간 차이가 있는지, 하위 범주 간 상관관계가 있는지 알아보았다. 이에 대한 결론 및 논의 내 용은 아래와 같다.

첫째, 경도지적장애 성인과 생활연령을 일치시킨 일반 성인 간의 질적 분석(전반적 평가, 분석적 평가) 시 차이가 있는지 살 펴보았다. 연구자는 경도지적장애 성인과 일반 성인의 SNS에서 추출한 문장을 읽으며 총체적 평가와 분석적 평가로 나누어 분 석을 실시하였다. 질적 분석의 하위 범주는 총체적 평가의 전반 적 인상과 분석적 평가의 세부적 인상인 맞춤법, 단어 사용, 조 사 사용의 적절성, 띠어쓰기로 연구자의 주관으로 분석하였다.

질적 분석의 전체 점수 결과 경도지적장애 성인 집단이 일반 성인 집단에 비해 연구자로부터 낮은 배점을 받은 것으로 나타 났으며 하위 범주별 결과 역시 전반적 인상, 맞춤법, 단어 사용, 조사 사용의 적절성, 띄어쓰기 모두에서 경도지적장애 성인 집 단이 일반 성인 집단에 비해 낮은 점수를 받았다. 이러한 결과 는 경도지적장애 성인 집단의 문장들이 통사 규칙적인 측면에 서 어색했을 뿐 아니라 맞춤법, 띄어쓰기에서의 오류가 나타났 기 때문이다. 또한 경도지적장애 집단이 일반 집단에 비하여 전체적인 내용을 조합하는 능력이 낮으며, 쓰기로 작문하는 능 력은 갖추고 있으나 적절한 단어를 사용하여 능숙하게 표현하 는 데에 미숙함을 보인다는 Joe(2009)의 연구가 본 연구의 결 과를 뒷받침하고 있다.
세부적 인상의 하위 범주별 점수 차를 살펴본 결과 가장 큰 격차를 보였던 것은 조사 사용의 적절성이며, 이어서 띄어쓰기, 맞춤법, 단어 사용의 순서로 나타났다. 먼저 경도지적장애 성인 집단의 조사 오류를 살펴보면 ' $\bigcirc \bigcirc$ 에 빵을 샀습니다., ' $\bigcirc$ 쿠키는 5,000원을 합니다.' 등으로 조사 사용에서 두드러지게 어색한 형태를 보였는데, 이는 Lee et al.(2015)의 경도지적장애 학생의 쓰기 발달 연구 결과와 일치하며 경도지적장애 학생들 이 문법 오류를 많이 보인다는 Lee(2014)의 연구 결과와도 맥 을 같이 한다. 두 번째로 큰 격차를 보였던 것은 띄어쓰기로 편 리성을 목적으로 의미에 영향을 주지 않으며 띄어쓰기를 종종 생략하는 일반 성인과는 달리 경도지적장애 성인 집단은 한 문 장 전체에서 띄어쓰기를 하지 않거나, '수목원 에서-', '-않을 게 요 등 의미와 품사에 대한 낮은 이해로 일반적이지 않은 오류 를 보였다. 위와 같은 형태로 띄어쓰기 오류(한 문장 전체에서 띄어쓰기를 하지 않은 오류, 낮은 조사 이해도로 인한 띄어쓰 기 오류)를 범할 경우, 문장의 중의성으로 인해 읽는 이에게 혼 동을 줄 수 있으며 의미 전달에 영향을 끼칠 수 있다. 따라서 이러한 결과는 경도지적장애 성인을 위한 쓰기 교육에 어휘와 알맞은 조사 사용과 관련된 교육이 이루어져야 할 것을 시사한 다. 세 번째는 맞춤법으로 일반 성인들의 문장들을 살펴보면 $\mathrm{SNS}$ 에서 많이 나타날 수 있는 유행어(예: 텅장, 혹쉬 등), 준말 (예: 토욜, 드뎌 등) 등 맞춤법에서는 오류를 보이나 읽었을 때 어색함이 없고 내용을 파악하는 데에 어려움이 없어 경도지적 장애 성인 집단과의 격차가 존재하는 것으로 사료된다. 유행어, 준말 등의 사용이 대부분이었던 일반 성인 집단과는 달리 경도 지적장애 성인 집단은 '재미 $\rightarrow$ 제미', '야외수업 $\rightarrow$ 야왜 수업, '더 나아 $\rightarrow$ 더 낳아' 등의 맞춤법 오류를 보였다. 또한 일반 성 인 집단은 주로 모음을 바꾸거나(예: 먹고 싶은데 $\rightarrow$ 먹고 싶은 디, 정말 $\rightarrow$ 증말 등), 문장의 끝에 음소를 추가함으로써(예: 먹 고싶거등, 머리잘랐당 등) 발음상의 표현에서 유희를 추구하는 형태를 보이는 반면, 경도지적장애 성인의 주된 오류는 자음 대치의 오류(밖에 $\rightarrow$ 박에, 벚꽃 $\rightarrow$ 벗꽃 등)로 어색한 형태를 보였다. 가장 작은 격차를 보였던 것은 단어 사용으로 이는 Jeong(2014)의 경도지적장애 집단과 일반 집단 간 어휘 다양도 에서 유의미한 차이를 보이지 않는다는 연구 결과와 일치한다.

둘째, 경도지적장애 성인과 일반 성인 간 양적 분석 시 차이 가 있는지 살펴보았다. 두 집단 간 하위 범주(맞춤법, 띄어쓰기, 
조사)의 차이를 알아보기 위해 기술통계를 실시한 결과 맞춤 법, 띄어쓰기, 조사의 평균과 표준편차의 차이가 있음을 알 수 있었다. 이러한 결과로 맞춤법, 띄어쓰기, 조사의 오류가 일반 성인 집단에 비하여 경도지적장애 성인 집단에서 많이 보인다 는 것을 알 수 있었다. 특히 조사에서 유의미한 차이를 보였는 데 이러한 결과는 조사 사용의 적절성에서 가장 큰 격차를 보 였던 질적 분석 결과와 일치하며, $\mathrm{Seo}(2017)$ 의 경도지적장애 성 인이 문자언어 상황에서 조사 오류의 빈도가 높다는 연구를 뒷 받침한다. 한편 두 집단 간 맞춤법과 띄어쓰기 오류에서는 유의 미한 차이를 보이지 않았는데 이는 질적 분석 결과와는 다르게 일반 성인의 유행어, 준말 등의 사용이 양적 분석 시 오류 단어 로 계수되어 경도지적장애 성인과 유의미한 차이를 보이지 않 았던 것으로 추측할 수 있다. 일반 성인 집단의 높은 유행어, 준 말 사용으로 인한 맞춤법 오류 빈도와는 다르게 경도지적장애 성인 집단의 문장에서는 유행어나 준말 사용으로 인한 맞춤법 오류를 찾을 수 없었는데 이러한 결과는 유행어를 이해하고 표 현하는 능력에서 일반 성인 집단에 비해 경도지적장애 성인 집 단이 유의미하게 낮은 점수를 보였다는 Cheon et al.(2017)의 연구 결과와 일치한다. 같은 맥락으로 Joe(2009)의 두 집단 간 맞춤법 오류 점수에서 유의미한 차이가 나타나지 않는다는 연 구 결과와 일치하며, 일반 성인들은 SNS상에서 글을 쓰는 시 간을 단축하기 위하여 음절 또는 음소를 생략하거나 줄여 쓰 는 경우가 빈번하며, 글 작성 중 오타가 발생하더라도 중요하게 여기지 않아 수정하지 않기 때문에 맞춤법, 띄어쓰기 등 형식 적 오류를 보인다는 $\operatorname{Kan}(2017)$ 의 연구와도 일치한다. 맞춤법, 띄어쓰기와 관련된 통계적인 유의미한 결과를 도출하지는 못 하였으나, 일반 성인들의 쓰기 오류는 SNS 사용에서만 주로 보 이는 양상으로 쓰기 발달의 지연으로 인한 경도지적장애 성인 의 쓰기 오류와는 질적인 차이가 존재함을 추측해 볼 수 있다. 또한 미디어를 활용한 정보 습득, 자신의 의사 표현 등 원만한 사회적 의사소통과 적절한 관계 형성을 위해서는 미디어상에 서 변화하는 언어 사용에 대하여 비판적인 관점이 아닌 사회. 문화적인 관점으로 주목해 보아야 할 것을 시사한다.

셋째, 두 집단별 하위 범주 간 연관성에 대해 알아보기 위하 여 상관관계를 살펴보았다. 맞춤법, 띄어쓰기, 조사 간 상관관 계를 살펴본 결과 두 집단 모두 조사와 띄어쓰기 간 유의미한 정적 상관이 있는 것으로 나타났으며, 맞춤법과 띄어쓰기 간, 맞춤법과 조사 간에는 연관성이 없는 것으로 나타났다. 경도지 적장애 성인 집단의 조사, 띄어쓰기에는 조사 사용에서의 오류 와 더불어 조사의 띄어쓰기 오류(예: 오빠 가-, 꽃 이-)가 많이 나타났는데 이러한 오류 양상으로 인하여 조사와 띄어쓰기 간 유의한 연관성이 나온 것으로 추측할 수 있다. 또한 단어 간 띄 어쓰기 오류가 많이 나타나는 일반 학생(Kim, 2011)과는 상이
하게 경도지적장애 성인 집단은 단어 내 띄어쓰기 오류의 빈도 가 높은 것으로 나타나 조사와 조사의 띄어쓰기에 대한 이해가 낮은 것을 알 수 있다. 이러한 결과는 경도지적장애 집단의 쓰 기 지도 시, 조사의 쓰임뿐 아니라 조사의 띄어쓰기에 대한 부분 도 함께 이루어져야 할 것을 시사한다. 반면 일반 성인 집단의 조사 띄어쓰기 오류를 살펴보면, 조사에서의 오류는 없으나 전 술한 내용과 같이 띄어쓰기에 주의를 기울이지 않아 조사 뒤 띄 어야 하는 문장도 붙여서 쓰는 형태(예: -오후에갈게)를 보여 서 로 유의한 연관성이 나온 것으로 추측해 볼 수 있다. 이러한 결 과는 조사 뒤 띄어쓰기를 해야 한다는 것을 알고 있음에도 불 구하고, SNS상에서 시간과 속도로 인한 경제성을 고려해 띄어 쓰기를 잘 하지 않는다는 $\operatorname{Kan}(2017)$ 의 연구 결과가 뒷받침한다.

본 연구의 제한점은 제한적인 지역, 한정적인 대상자 수로 본 연구 결과를 일반화하는 데에 어려움이 있을 수 있다는 것이며 일반 성인의 인지 수준을 통제하지 못하였다는 점이다. 또한 양 적 분석 시 다양한 쓰기 오류 양상 가운데 맞춤법, 띄어쓰기, 조사 오류만 분석하였다는 점이다. 따라서 후속연구에서는 지 역 및 대상자 수 확대와 더불어 일반 성인의 인지 수준을 평가 할 수 있는 검사를 활용하여 통제하여야 할 것이며, 쓰기에서 나타날 수 있는 더 다양한 오류 양상을 분석하는 연구가 이루 어져야 할 것이다.

위와 같은 제한점에도 불구하고 본 연구는 미디어 문식성을 위해 시도된 예비연구로서 이전에 충분히 시도되지 못했던 경 도지적장애 성인의 $\mathrm{SNS}$ 에서 나타나는 자발화 분석 연구를 시 행하였다는 데에 의의가 있다고 사료되며, 이러한 분석 결과를 통해 SNS와 같은 미디어를 활용한 쓰기 관련 교육 개발의 기 초 자료로 활용될 수 있기를 기대한다. 또한 화용과 문해 능력 의 결함으로 SNS 내 의사소통에 어려움을 겪는 경도지적장애 성인들을 위해 쓰기 오류 양상을 기초 자료로 하여 미디어를 활용한 언어적 중재를 실시한다면, 비대면적인 상황, 즉 미디어 내 상황에서도 성공적인 의사소통을 할 수 있을 것으로 사료되 며, 나아가 이는 경도지적장애 성인의 직업생활, 대인관계 등에 도 긍정적인 영향을 미칠 것이다.

중심 단어 : 경도지적장애성인·미디어 문식성·SNS 쓰기·쓰기 오류.

\section{Ethical Statement}

The study was approved by the Institutional Review Board of Daegu University of Graduate Studies (1040621-202009-HR-022).

\section{Acknowledgments}

The authors thank all the students who participate in this study.

\section{Declaration of Conflicting Interests}

There are no conflict of interests. 


\section{Funding}

This study was conducted with the support of academic research funds by Daegu University in 2019 (20190535).

\section{Author Contributions}

S.L. designed and performed experiments, analyzed data, and wrote the paper; S.L. designed and performed experiments in the clinic; W.K. provided statistical analysis and critical revision; S.L. designed experiments, analyzed data, and wrote the paper. Also, the authors discussed the results together and implications and commented on the manuscript at each stage.

\section{ORCID iDs}

Soyeon Lim

Whasoo Kim

https://orcid.org/0000-0002-6399-1927 https://orcid.org/0000-0003-4787-4824

\section{REFERENCES}

Cheon, J., Kim, W., \& Rhee, K. (2017). A study of fad words recognition and usage characteristics of adults with mild intellectual disability. Journal of Special Education: Theory and Practice, 18(2), 41-62.

Choi, J. H. (2016). Self-esteem and SNS activities in 20s. Korea Information Society Development Institute, 17(3).

Choi, J. H., Seo, H., Shim, Y. T., Lee, D. Y., Choi, M. S., Kim, J. J., et al. (2007). Teaching and Learning Methods of the Department of Korean Language. Seoul: Youkrack.

Graham, S., Berninger, V., \& Fan, W. (2007). The structural relationship between writing attitude and writing achievement in first and third grade students. Contemporary Educational Psychology, 32(3), 516-536.

Hwang, S. T., Kim, J. H., Park, K. B., Chey, J. Y., \& Hong, S. H. (2012). Korean Wechsler Adult Intelligence Scale-IV. Seoul: Inpsyt.

Jang, S. Y. (2016). A study on the proverb comprehension of students with intellectual disability (Unpublished master's thesis). Daegu University, Gyeongsan.

Jeong, H. N. (2014). Characteristics of descriptive writing of children with mild intellectual disabilitie: Focus on 4th and 6th graders (Unpublished master's thesis). Dankook University, Yongin.

Joe, E. H. (2009). A comparative study on the narrative writing abilities of students in mild mental retardation and normal children (Unpublished master's thesis). Myongji University, Seoul.

Jung, H. J. \& Lee, J. Y. (2008). The characteristics of borderline intellectual functioning children. Korean Journal of Special Education, 42(4), 43-66.

Kan, H. B. (2017). The effect of' Kakao Talk' language on writing for the college students. The Korean Journal of Literacy Research, 19, 39-60.

Kang, E. Y. (2007). The effect that repeated speaking activities after watching multi-animations have on type-token ratio (TTR) and expansion of semantic relations in mentally retarded children (Unpublished master's thesis). Deagu University Graduate School of Education, Gyeongsan.

Kim, G. E. (1991). A comparative study of presupposition ability between normal and mentally retarded children (Unpublished master's thesis). Ewha Womans University, Seoul.

Kim, I. H. (2011). The actual state of the use of word spacing and a study on the map plan: For the first year of high school (Unpublished master's thesis). Ajou University, Suwon.

Kim, W. S. \& An, S. Y. (2017). Relations of competence of social communication, mind of theory, and popularity among children with normal language ability and adolescent with mild intellectual disability. Journal of Intellectual Disabilities, 19(4), 229-248.

Kim, Y. H. (2002). Language of Mentally Retarded Children. Seoul: Special Education.

Kim, Y. H. \& Han, K. E. (2008). Effects of blog activities on written expres- sion of students with mental retardation. Journal of Special Education, 20, 25-51.

Kim, Y. T., Hong, G. H., Kim, K. H., Chang, H. S., \& Lee, J. Y. (2009). Receptive Expressive Vocabulary Test (REVT). Seoul: Seoul Community Rehabilitation Center.

Lee, C. S. (2004). Theoretical Exploration of Early Childhood Language Education. Seoul: Hakjisa.

Lee, E. H. (2010). A study on educational contents of an article: with a focus on the unit 'Writing (Unpublished master's thesis). Pusan National University, Busan.

Lee, H. B., Kim, W. S., \& Park, J. S. (2015). Text knowledge on diary of students with mild intellectual disabilities. Journal of Intellectual Disabilities, 17(4), 77-92.

Lee, J. H. (2014). The aspects of writing ability development in expressive writing according to the basic scholastic ability of students with mild mental retardation (Unpublished master's thesis). Dankook University, Yongin.

Lee, J. M. \& Yoon, N. R. (2011). The effects of task value, Twitter self-efficacy, and social presence on learning satisfaction on Twitter discussion. Journal of Korean Association of Information Education, 16(1), 51-60.

Lee, J. M., Oh, S. E., \& Kim, N. H. (2013). Predictability of team efficacy and learning achievement by shared mental model in SNS supported collaborative learning (SSCL). The Journal of Educational Information and Media, 19(3), 315-335.

Lee. J. S. (2015). A study on ways vitalize SNS through an analysis of senior adult's needs (Unpublished master's thesis). Hanyang University, Seoul.

Lee, S. B. (1994). The composition skills of children with mentally retarded. Journal of Special Education, 1, 73-99.

Lee, Y. J. \& Lee, J. S. (1990). A study of young children's written language development and the effects of non-directive teaching method on the development of written language. The Journal of Educational Research, 28(2), 105-123.

Lim, K., Kang, M. S., \& Shin, S. W. (2012). The study on experts' perceptions on usage elements of SNSs and the investigation on the priority of the elements for SNSs' educational use through importance-performance analysis. Journal of Educational Technology, 28(4), 925-952.

McLeavey, B. C., Toomey, J. F., \& Dempsey, P. J. (1982). Nonretarded and mentally retarded children's control over syntactic structures. American Journal of Mental Deficiency, 86(5), 485-494.

Olson, D. R. \& Oatley, K. (2014). The quotation theory of writing. Written Communication, 31(1), 4-26.

Seo, D. H. (2017). The analysis study on students with mild intellectual disability's the spoken and written language characteristics in story (Unpublished master's thesis). Deagu University Graduate School of Education, Gyeongsan.

Son, E. N., Park, H., \& Park, C. H. (2013). A study of the phonological characteristics of mentally retarded children by the level of intellectual disability and word length. Journal of Speech-Language and Hearing Disorders, 22(2), 163-179.

Yoon, J. A. \& Lee, Y. (2014). Analysis on the changes of disabled students' writing skills and non-disabled student's attitude toward them with collaborative learning using SNS (social network service) in the inclusive educational environments. Journal of Learner-Centered Curriculum and Instruction, 14(7), 397-422.

Yu, G. \& Jeong, E. H. (2008). A comparative study on the characteristics of writing knowledge among children with specific language impairment, those with borderline intelligence-language impairment, and normal children. Korean Journal of Special Education, 43(2), 217-236.

Yu, G. (2010). Error analysis of writing in students with hearing impairment by diary analysis. The Journal of Special Children Education, 12(4), 433450. 


\section{APPENDIX}

\section{두 집단 오류 문장 예시}

\begin{tabular}{|c|c|c|}
\hline 하위 범주 & 경도지적장애 성인 & 일반 성인 \\
\hline \multirow[t]{5}{*}{ 맞춤법 } & (1) 선생님한태 문의해봣는데 $\bigcirc \bigcirc$ 이 괜찮데요 & (1) 혹쉬 내일도 비가오지 않을까? \\
\hline & (2) 여기는 정말 맛있는 구미맞집이에요 & (2) 귀여워서 텅장 순삭이다 \\
\hline & (3) 많이 싸이면 눈사람을 만들 것이다 & (3) 축하해주신분들 모두 복 받으세욤 \\
\hline & (4) 안경벗는게 더 낳아 & (4) 지금 나는 세상에서 젤 행복하당 \\
\hline & (5) 혁이랑 체육대회 제미있었어 & (5) 나 어제 $\bigcirc \bigcirc$ 이랑 $\bigcirc \bigcirc$ 미용실 가서 머리잘랐당 \\
\hline \multirow[t]{6}{*}{ 띄어쓰기 } & (1) 네형오랜만이네요 & (1) 정리 중인데 나중에 올려줄게 \\
\hline & (2) 모두들 잘먹을 게요 & (2) 설때 입으려고 보관해뒸다 \\
\hline & (3) 수목원 에서 가서 찍은 사진입니다 & (3) 긴듯 짧은듯 소중한 시간이었고 좋은 사람들 만나서 \\
\hline & (4) 교수님혹시그소식들으셨나요 & 행복했습니다 \\
\hline & (5) 저도요새밖에안나가고있어요 & (4) 캐나다 잘 갔다오고 올때 선물 사와 \\
\hline & & (5) 오창에서 강릉바로가는 버스잇음 \\
\hline \multirow{5}{*}{ 조사 } & (1) 대원당에 빵을 샀습니다 & (1) 너 지금 강의실에 수업 듣고 있어? \\
\hline & (2) 미국음식이양이 많아서 나는 도전이 실패했다 & \\
\hline & (3) 다마에쿠키는 5,000 원을 합니다 & \\
\hline & (4) 광안리에서 바다에서 빠져서 친구가 웃엇습니당 & \\
\hline & $\begin{array}{l}\text { (5) 포항에아침먹고 경주엣 취업설명회하고 } \\
\text { 놀이기구를 탔다 }\end{array}$ & \\
\hline
\end{tabular}

